\title{
Factors influencing farmer acceptance and uptake of new white clover cultivars
}

\author{
B. BELGRAVE \\ AgResearch Grasslands, Private Bag 11008, Palmerston North
}

\begin{abstract}
White clover is important to New Zealand pastoral farming yet uptake of new agronomically superior cultivars by farmers is slower than expected. Three main areas which explain why this is occurring are: 1 . The need to demonstrate economic benefits due to superior agronomic performance of new cultivars to overcome barriers such as price and farmers satisfaction with existing products. 2. Farmers are influenced by advice of seed retailers/extension personnel, their knowledge of white clover cultivars, local research, and their economic situation. 3. White clover seed quantity and quality has been adversely affected by poor weather conditions at flowering and harvest over the last 3 or 4 years. Seed availability is also being affected by the cultivar change regulations and the changing land use patterns of Canterbury. The problem is magnified by the increasing number of white clovers being grown on a decreasing land base. For greater uptake and use of new white clovers, strategies that deal with all three areas are required.
\end{abstract}

Keywords: buying decision, economic benefit, farmer use, seed availability, white clover

\section{Introduction}

White clover is considered the most important forage legume in New Zealand (Brock et al. 1989). It is important to New Zealand pastoral farming because:

- White clover $\mathrm{N}$-fixation is estimated to be 1.6 million tonnes $\mathrm{N}$ per year, worth $\$ 1.5$ billion (Caradus et al. 1996).

- White clover's high quality forage is estimated to have a value over grasses worth $\$ 1.3$ billion (Caradus et al. 1996).

- It is complementary to grass species in pasture mixtures.

- Cultivars have a high degree of plasticity to a range of environments and managements.

Prior to 1978 Grasslands Huia and uncertified white clover were the main white clovers used in New Zealand. Today more than $10 \mathrm{NZ}$ cultivars are available, all of which have more specialised uses than Huia and are agronomically superior (Woodfield \& Caradus 1994).

This paper will discuss the major factors limiting the uptake of new white clover cultivars by farmers despite their clear agronomic advantages. It should be noted that while the problems are quite separate, they are all inter-linked and that for improved uptake a total package is required.

The three key areas influencing the uptake and use of new white clover cultivars are:

1. The ability to demonstrate economic benefits of the superior agronomic performances.

2. Factors influencing farmers buying decisions.

3. Seed availability.

\section{Demonstration of economic benefits due to superior agronomic performance}

\section{Farmer satisfaction with existing products}

Uptake of new white clover cultivars is limited where farmers are satisfied with the cultivar they are using. If a farmer perceives his current cultivar allows him to reach the animal and pasture performance goals of his farming system, he will be reluctant to change. The superior agronomic features of a new cultivar will be of little interest unless a clear economic benefit is demonstrated from this agronomic advantage, e.g. white clover flea. If a new cultivar is to be used by these farmers, the marketing strategy needs to focus on demonstrating the economic benefits in addition to the superior agronomic performance and features.

\section{Price}

Like any purchasing decisions, price of white clover seed is an important factor. Many farmers buy on price irrespective of whether it is agronomically superior or not. Again a clear demonstration of the economic benefits would allow farmers to see that while the seed may be more expensive per $\mathrm{kg}$, the dollar benefits/ha are significantly greater. Unless new varieties are marketed in this way higher seed costs will continue to limit uptake.

For example, Grasslands Tahora white clover, the first New Zealand bred proprietary white clover, had well documented agronomic advantages over Huia in 
hill country, set-stocked and summer-dry environments (Brock 1988; Chapman et al. 1993). Tahora sales were significantly increased when the Challenge Seeds Roadshow demonstrated that these agronomic advantages were reflected in higher stock carrying capacities, $\mathrm{N}$-fixation levels, and animal performance (Chapman et al. 1993). Despite higher seed prices, farmer acceptance of Tahora was markedly increased through Tahora being marketed as a product with transparent economic benefits derived from its superior agronomic attributes.

\section{Factors influencing farmers' buying decisions}

Aproximately 200,000 ha or $3 \%$ of all arable land is resown to pasture each year (Lancashire 1985). The key factors influencing farmers buying decisions, other than price, appear to be:

- knowledge and advice given by seed retailers and extension personnel

- farmer knowledge

- impact of major research and breeding efforts in regions where this is conducted

- economics of the end user.

\section{Knowledge and advice given by seed retailers and extension personnel}

Seed retailers and extension/advisory personnel have more contact with, and confidence of, farmers on a day to day basis than do other groups in the industry (Belgrave et al. 1990).

A recent survey revealed that company retail seed representatives were the most popular source of information for pasture cultivars (Belgrave et al. 1990). Therefore their knowledge of the agronomic advantage and economic benefits from new cultivars is vital to influencing a farmer's buying decision. Current indications are that most seed representatives are not in a position to give this information (through no fault of their own). Opportunities to influence farmers to use improved white clover cultivars are therefore being missed. Of greater concern is the diminishing number of seed representatives as retailers are changing to a more 'supermarket' approach, e.g. Farmlands, Wrightson bulk barns. Therefore stock agents are often the only company representatives in regular contact with farmers and offer untapped potential for influencing farmers. Stock agents regularly review with farmers animal performance and are potentially ideally placed to recognise the importance of improved pasture performance and subsequent livestock returns to farmers using improved white clover cultivars. In marketing strategies, a greater resource needs to be put into not only upskilling seed representatives but also stock agents otherwise farmers' buying decisions will be based on poor or little information.

Associated with this, is the level of information available to the retailer. Cultivars which have the best product support tend to gain the most commitment from retailers, and be recommended irrespective of its suitability. Therefore obtaining retailer commitment through product support, pricing and promotional information will have an impact on what cultivar is sold by them to farmers.

If the 'supermarket' approach for retailing seed continues, then marketing companies need to provide information packages at the point of sale to assist farmers in making an informed buying decision.

Extension/advisory personnel also have regular farmer contact and have the potential to impact on cultivar choice. Specialist pasture advisers such as Grassline $^{\mathrm{TM}}$ have been very successful in demonstrating economic benefits of new white clover cultivars, and are having a major impact on influencing farmers to use agronomically superior white clover cultivars. Other advisory groups have the resource and infrastructure to influence farmer clients, but are not necessarily pasture specialists. This industry group, like the seed representatives, need to be targeted in marketing strategies so they have the knowledge and product support to accurately advise farmers.

\section{Farmer knowledge}

The level of farmer knowledge is critical in the uptake of new white clover cultivars. A farmer with little knowledge of a cultivars benefits (agronomic and economic) is more likely to look at seed price or suffer from confusion due to the large number of available cultivars. Not knowing which cultivar is appropriate for his situation often leads to purchase of the cheapest, rather than the best seed for their situation.

Dairy farmers appeared to be more knowledgeable of new cultivars than other farming sectors (Belgrave et al. 1990). This may be a result of new cultivar benefits being quickly and clearly measurable through 'milk in the vat'. Measuring benefits is more difficult for other farming sectors and may reflect their more conservative adoption practices and slower uptake of new cultivars. Farmers frequently have a 'seeing is believing' attitude (Belgrave et al. 1990). Demonstration paddocks established through schemes such as Focus Farms, MRDC monitor farms, TBG programmes (e.g. More summer milk and Pastures for high quality chilled meat), and AGMARDT funded premium pasture programmes are therefore having a large impact. These schemes highlight the economic benefits of new cultivars, and increase farmer awareness and knowledge of these cultivars, and what they can do to improve their farming 
system. Over time this improved knowledge should allow more rapid uptake of new white clover cultivars.

\section{Impact of major research and breeding efforts in regions where this is conducted}

Cultivars that have been bred in a particular are likely to be taken up more rapidly by local farmers than cultivars bred and developed in others region irrespective of agronomically suitability (Belgrave et al. 1990). Grasslands Demand white clover in the southern South Island and Grasslands Prestige and Grasslands Challenge white clovers in the northern North Island are examples of where there is a huge local expectation, and seed requirements currently exceed supply. Farmers in these regions are very aware of these cultivars, and this highlights the point that regional research results impact on cultivars farmers use.

\section{Economics of the end user}

Uptake parallels farmers financial viability. When economic returns to the farmer are low the use of new cultivars is also likely to be low, irrespective of advice, knowledge and the desire to use the new cultivar. The uptake of new cultivars will therefore mirror various farming sectors economic up and downturns. This factor is often difficult to take into consideration when formulating marketing strategies but must be considered.

\section{Seed availability}

Reliable seed availability is essential for a cultivar uptake and use. A number of factors have a major impact on companies ability to deliver on this.

\section{Weather conditions}

Adverse weather conditions at establishment, flowering and/or harvesting during the last 4-5 years have had quite devastating effects on white clover seed crops. Poor harvests have impeded the commercial development of several white clover cultivars, with many companies unable to supply the market demand generated through their marketing strategies and promotion. This has resulted in some farmers using second or third choice cultivars, and damages the reputation of the first choice cultivar. When seed shortfalls occur, companies must resist the temptation to release poor quality seed to satisfy the demand as this will only further damage the reputation of the cultivar.

\section{Cultivar change}

The mandatory five year cultivar change regulations for seed (Clifford et al. 1990; Clifford et al. 1996) are limiting the production and availability of seed of new white clover cultivars. Many suitable growers are not prepared to outlay the expense and work involved for cultivar change. New cultivars require the production expertise of these growers, and the whole industry needs to put resources into coming up with practical methods whereby this expertise can be utilised. A strategy to attract these growers could be focussed on the superior yield potential of new cultivars especially the small to medium leaved cultivars (Clifford et al. 1990). Obtaining these superior yields requires more precise management, and it is essential that expert knowledge and advice is given to farmers to ensure these higher yields are achieved (Clifford et al. 1990; Clifford et al. 1996). Consideration should be given to contract structures that compensate growers for lower yielding larger-leaved white clover cultivars, so that satisfactory area can be procured.

\section{Land availability}

The ideal white clover growing areas in Canterbury are steadily diminishing, owing to competition from other arable crops, 'life-style' blocks, and the steady dairy conversion occurring on irrigated arable Canterbury land (Clifford et al. 1996). Therefore more white clover is being produced in marginal/higher risk environments, where yields are less reliable. This also reduces both seed quality available to the end user and the quantity available for the seed company to market. The other complicating factor in the diminishing land base available is the number of white clover cultivars in the certification system (Clifford et al. 1996). Each new cultivar grown means those paddocks are unavailable for growing other white clover cultivars for 5 years. The number of cultivars available is adding to the pressure on land availability, and as with the cultivar change regulation this issue also needs to be urgently dealt with by the whole industry.

\section{Conclusion}

There is no single answer for improving the uptake and farmer acceptance of new cultivars. To make significant progress a total package addressing seed availability, how to influence the buying decisions of the farmer, and being able to market/demonstrate the economic benefits of agronomic superiority, needs to be put in place for each new cultivar.

\section{References}

Ball, P.R.; Field, T.R.O. 1985. Productivity and economics of legume-based pastures and grass swards receiving fertiliser nitrogen in New Zealand. pp. 47-55. In: Forage Legumes for Energy-Efficient 
Animal Production. Proceedings of a Trilateral Workshop, Palmerston North, New Zealand, April 1984.

Belgrave, B.R.; Brock, J.C.; Watt, P.C.; Wewala, S. and Sedcole, J.R. 1990. A survey of farmer knowledge and use of pasture cultivars in New Zealand. New Zealand Journal of Agricultural Research 33: 199-211.

Brock, J.L. 1988. Evaluation of New Zealand bred white clover cultivars under rotational and set-stocking with sheep. Proceedings of the New Zealand Grassland Association 49: 203-207.

Brock, J.L.; Caradus, J.R.; Hay, M.J.M. 1989. Fifty years of white clover research in New Zealand. Proceedings of the New Zealand Grassland Association 50: 25-39.

Caradus, J.R.; Woodfield, D.R.; Stewart, A. 1996. Overview and vision for white clover. Agronomy Society of New Zealand Special Publication No. 11/Grassland Research and Practice Series No. 6: $1-6$.

Chapman, D.F.; Mackay, A.D.; Devantier, B.P. and Dymock, N. 1993. Impact of white clovers on nitrogen fixation and livestock production in a New Zealand hill pasture. Proceedings International Grassland Congress 17: 421-423.

Clifford, P.T.P.; Baird, I.J.; Grbavac, N. and Sparks, G.A. 1990. White clover soil seed loads and effects on requirements and resultant success of cultivarchange crops. Proceedings of the New Zealand Grassland Association 52: 95-98.

Clifford, P.T.P.; Sparks, G.A.; Woodfield, D.R. 1996. The intensifying requirements for white clover cultivar change. Agronomy Society of New Zealand Special Publication No. 11/Grassland Research and Practice Series No. 6: 19-24.

Lancashire, J.A. 1985. Some factors affecting the rate of adoption of new herbage cultivars. Using Herbage Cultivars. Grassland Research and Practice Series No 3: 79-87.

Woodfield, D.R. and Caradus, J.R. 1994. Genetic improvement in white clover representing six decades of plant breeding. Crop Science 34: 12051213. 